\title{
Prenatal Development of Antioxidant Enzymes in Rat Lung, Kidney, and Heart: Marked Increase in Immunoreactive Superoxide Dismutases, Glutathione Peroxidase, and Catalase in the Kidney
}

\author{
HIDEMASA HAYASHIBE, KOHTARO ASAYAMA, KAZUSHIGE DOBASHI, AND KIYOHIKO KATO
}

Department of Pediatrics, Yamanashi Medical College, Yamanashi, Japan

\begin{abstract}
The immaturity of antioxidant capacity in the lung in preterm newborn infants is postulated to contribute to the development of hyperoxic lung injury. Antioxidant enzymes in fetal lung, comprised of copper-zinc (cytosolic) and manganese (mitochondrial) superoxide dismutases, glutathione peroxidase, and catalase, have been reported to increase during the late gestational period. To determine whether such maturation of antioxidant capacity occurs in other tissues, we have evaluated the development of these four enzymes from d 18 to 22 of gestation in rat lung, kidney, and heart. To resolve the confusion in the reported levels of lung superoxide dismutases, the two isoenymes were assayed separately by specific RIA. The growth of the kidney exceeded that of the whole body during this period, while the growth of the lung and heart did not. The concentrations of the four antioxidant enzymes in lung and kidney increased in a stepwise manner during this period, and the magnitude of the change for each enzyme was greater in the kidney than in the lung. On the other hand, the only significant change in the concentrations of heart antioxidant enzymes observed was a mild increase in the glutathione peroxidase concentration from d 20 to 22. These results suggest that the prenatal maturation of antioxidant capacity occurs earlier in the heart and later in the kidney than in the lung, and that the immaturity of antioxidant capacity could make the fetal rat kidney vulnerable to free radical-mediated injury. (Pediatr Res 27: 472-475, 1990)
\end{abstract}

\section{Abbreviations}

CuZnSOD, copper-zinc superoxide dismutase

MnSOD, manganese superoxide dismutase

GPX, glutathione peroxidase

CAT, catalase

SOD, superoxide dismutase

In recent years, increasing clinical and experimental data have provided evidence that cell injury mediated by active oxygen species contributes to the pathogenesis of events in numerous diseases such as hyperoxic lung injury (1) and ischemia-reperfu-

Received August 14, 1989; accepted January 10, 1990.

Correspondence and reprint requests: Hidemasa Hayashibe, MD, Department of Pediatrics, Yamanashi Medical College, 1110 Shimokato, Tamahocho, Nakakomagun, Yamanashi 409-38, Japan.

Supported in part by Grant-in-Aid 63570431 from the Ministry of Education (Japan). sion injury involving a variety of organs including heart (2) and kidney (3). The antioxidant enzymes, comprised of cytosolic CuZnSOD, mitochondrial MnSOD (EC 1.15.1.1), GPX (EC 1.11.1.9), and CAT (EC 1.11.1.6), afford protection by reducing the cellular concentration of active oxygen species (4). In special relevance to bronchopulmonary dysplasia, several previous studies focused on prenatal development of pulmonary antioxidant enzymes in the rat (5-8). The activities of total SOD, GPX, and CAT in lung were invariably found to be low before term and the low activities are considered to account, in part, for the vulnerability of premature newborn lung to hyperoxia. However, the two SOD isoenzymes were measured in only two previous studies $(7,8)$ and the data were conflicting.

Part of the confusion is due to the limited sensitivity and specificity of the biologic SOD activity assays generally used. The activity assays detect all SOD-like activities, and are not specific to each form of intracellular SOD. Furthermore, a relatively low concentration of MnSOD in the tissues of rats compared with that in other species (9) makes biologic activity assays more prone to interference when applied to rat tissue homogenate. The specific RIA for rat MnSOD and CuZnSOD (10) have obviated the concerns regarding activity assays for SOD, although they do not measure biological activity. These assays have enabled us to measure CuZnSOD and MnSOD accurately not only in fetal lung, but also in smaller tissues in fetal rat.

In our present study, we evaluated the development of $\mathrm{Cu}$ ZnSOD, MnSOD, GPX, and CAT from d 18 to 22 of gestation in rat lung, kidney, and heart. Using the specific assays, we demonstrated that both CuZnSOD and MnSOD in the lung increased significantly during the observation period. We also revealed that a maturation of antioxidant enzymes similar to that in the lung occurred in the kidney.

\section{MATERIALS AND METHODS}

Animal treatment. Female Sprague-Dawley rats (Japan SLC Inc., Shizuoka, Japan), age 12 to $14 \mathrm{wk}$, were allowed free access to water and standard feed. Breeding was accomplished by placing male and female rats together overnight and checking for sperma-positive vaginal smears the next morning. The midpoint of the cohabitation period was considered the onset of pregnancy. Premature pups were delivered by hysterotomy with the dam under pentobarbital anesthesia $(201 \mu \mathrm{mol} / \mathrm{kg} ; 50 \mathrm{mg} / \mathrm{kg})$ on $\mathrm{d}$ 18,20 , or 22 of gestation. The litters consisted of 10 to 13 pups. The pups were immediately weighed and decapitated before spontaneous breathing occurred. Two to four litters were killed at each time point of the study. The lungs, kidneys, and hearts were excised, washed with PBS, and blotted with gauze: The 
organs were weighed and pooled to obtain at least $80 \mathrm{mg}$ of tissue for each sample, and then kept frozen at $-80^{\circ} \mathrm{C}$.

Homogenate preparation and biochemical analyses. The tissues were homogenized with 20 times their vol of $10 \mathrm{mM}$ potassium phosphate buffer containing $0.01 \%$ digitonin ( $\mathrm{pH} 7.4$ ) in a Potter-Elvehjem type glass-Teflon pestle homogenizer (Wheaton Instruments, Millville, NJ), and then sonicated on ice for $30 \mathrm{~s}(15 \mathrm{~s} \times 2)$, using an Ultrasonic cell disrupter UR-200P (Tomy Seiko, Tokyo, Japan). The sonicate was centrifuged at $13000 \times g$ for $5 \mathrm{~min}$, and the supernatant was stored frozen in aliquots at $-80^{\circ} \mathrm{C}$ until assayed.

The RIA for CuZnSOD and MnSOD have been described (10). The technical data for these assays are as follows. The sensitivity, defined as the minimum concentration of enzyme that displaced $5 \%$ of radioactivity from antibody sites, was 28 $\mathrm{pM}$ at the antiserum dilution of $1: 2.5 \times 10^{5}$ for MnSOD assay, and the dilution curve of the rat liver homogenate paralleled the standard curve at the concentrations ranging from 56 to $909 \mathrm{pM}$. The sensitivity for the CuZnSOD assay was $91.8 \mathrm{pM}$ at the antiserum dilution of $1: 5 \times 10^{4}$ and parallelism was obtained at concentrations ranging from $184 \mathrm{pM}$ to $2.94 \mathrm{nM}$. When the eluate from gel filtration chromatography was assayed, a single authentic peak of immunoreactivity was recovered for both MnSOD and CuZnSOD. Intraassay coefficient of variation was $9.1 \%$ for the MnSOD and $6.8 \%$ for the CuZnSOD assay. Interassay coefficient of variation was $9.2 \%$ for the MnSOD and $11.7 \%$ for the CuZnSOD assay. The labeled enzyme was stable for $2 \mathrm{wk}$ when stored unfrozen at $4^{\circ} \mathrm{C}$. The immunoreactivity for both MnSOD and CuZnSOD was stable when stored at $-80^{\circ} \mathrm{C}$, even after three cycles of freezing and thawing.

GPX activity was assayed by the method described previousiy (11). CAT activity was assayed spectrophotometrically and calculated using the first order rate constant (12) in the samples of kidney and heart. Because the CAT activity in the samples of lung was below the detection limit of this assay, the activity in the lung homogenates was assayed polarographically with a type PO-100A oxygen electrode (Yanagimoto Mfg. Co., Ltd., Kyoto, Japan) as described previously (13). Protein was measured by the technique of Lowry et al. (14).

Statistics. The data are presented as the means \pm SEM. Statistical significant was determined by the method of least significant difference, calculated after one-way analysis of variance.

\section{RESULTS}

Body wt, organ wt, and organ/body wt of fetal rats. Table 1 lists the number of litters studied, total numbers of pups, the body wt, organ wt, and organ wt relative to body wt of the fetal rats. The fetus grew rapidly (2.5-fold) between d 18 and 20 , but more slowly (1.5-fold) between d 20 and 22 . Similarly, the wt of lung, kidney, and heart increased markedly between d 18 and

Table 1. Body wt, organ wt, and organ/body wt of fetal rats*

\begin{tabular}{lccc}
\hline & \multicolumn{3}{c}{ Fetal age $(\mathrm{d})$} \\
\cline { 2 - 4 } & 18 & 20 & 22 \\
\hline Litters $(n)$ & 4 & 4 & 2 \\
Pups $(n)$ & 44 & 47 & 22 \\
Body wt $(\mathrm{g})$ & $1.64 \pm 0.02$ & $4.18 \pm 0.09 \dagger$ & $6.22 \pm 0.09 \ddagger$ \\
Organ wt $(\mathrm{mg})$ & & & \\
$\quad$ Lung & $51 \pm 1$ & $129 \pm 4 \dagger$ & $146 \pm 6 \ddagger$ \\
$\quad$ Kidney & $7 \pm 1$ & $29 \pm 1 \dagger$ & $50 \pm 1 \ddagger$ \\
$\quad$ Heart & $8 \pm 1$ & $20 \pm 1 \dagger$ & $34 \pm 1 \ddagger$ \\
Organ/body wt (mg/g) & & & \\
$\quad$ Lung & $31 \pm 1$ & $31 \pm 1$ & $24 \pm 1 \ddagger$ \\
$\quad$ Kidney & $4.6 \pm 0.1$ & $6.9 \pm 0.1 \dagger$ & $8.1 \pm 0.2 \ddagger$ \\
$\quad$ Heart & $5.2 \pm 0.1$ & $4.8 \pm 0.1 \dagger$ & $5.5 \pm 0.2 \ddagger$ \\
\hline
\end{tabular}

* Data are means \pm SEM. Paired organs (i.e. lungs and kidneys) were combined and weighed.

$\dagger p<0.01$ (vs. $18 \mathrm{~d}$ ).

$\ddagger p<0.01$ (vs. $20 \mathrm{~d}$ ).
20 , but less markedly between $\mathrm{d} 20$ and 22 . Only the growth rate of kidney exceeded that of the whole body in this period, the kidney/body wt increasing 1.8 -fold between $d 18$ and 22 . The lung/body wt was unaltered between $\mathrm{d} 18$ and 20 , and decreased thereafter. The heart/body wt tended to decrease between d 18 and 20, and then returned to the level of $\mathrm{d} 18$ at $\mathrm{d} 22$.

Antioxidant enzymes in lung homogenate. The concentrations of the four antioxidant enzymes per mg protein in the homogenates of fetal lungs obtained at 18,20, and $22 \mathrm{~d}$ of gestation are summarized in Figure 1. The level of each enzyme studied increased in a stepwise manner from d 18 to 22 . The increases in the concentrations of CuZnSOD, MnSOD, GPX, and CAT from d 18 to 22 were $1.5-, 2.2-, 1.4-$, and 2.5 -fold, respectively. Table 2 lists the relative increase in mean total enzyme content per organ calculated as the product of the concentration per $g$ tissue $\times$ mean organ wt and expressed as the ratio to the value at $\mathrm{d} 18$. From $\mathrm{d} 18$ to 20 , the increase in each antioxidant enzyme per lung paralleled the organ growth (i.e. approximately 2.5 fold). On the other hand, the increase in each enzyme from $\mathrm{d} 20$ to 22 exceeded the lung growth rate.

Antioxidant enzymes in kidney homogenate. As shown in Figure 2, the concentration of each antioxidant enzyme also increased in the kidney in a stepwise manner, and more markedly than in the lung. The increases in the concentrations of $\mathrm{Cu}$ ZnSOD, MnSOD, GPX, and CAT from d 18 to 22 were 1.7-, 2.5-, 2.1-, and 3.3-fold, respectively. The rate of increase in the mean kidney content of each enzyme exceeded the organ growth rate throughout the observation period (Table 2 ). The calculated

\section{Lung}


GESTATIONAL AGE (days)
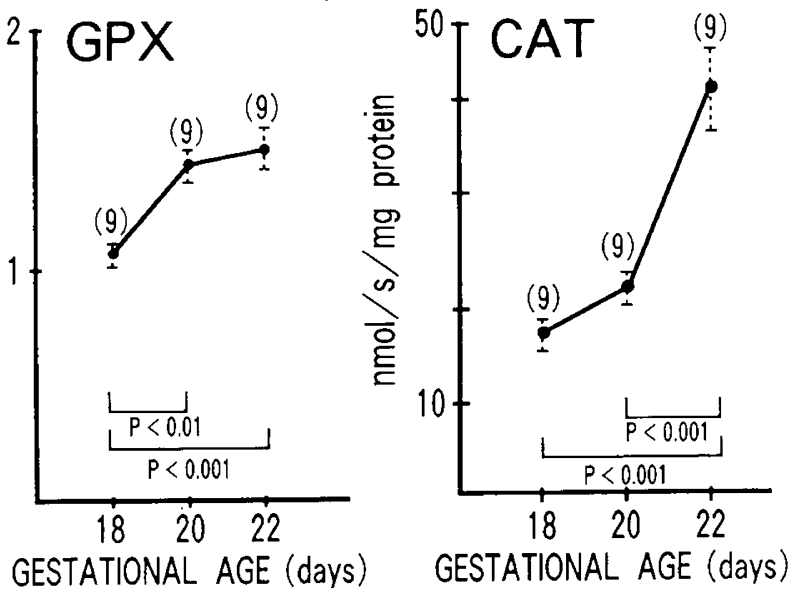

Fig. 1. Antioxidant enzymes in fetal rat lung homogenates. The brackets indicate SEM. The abscissa represents gestational d. The figures in parentheses are the number of observations. 
Table 2. Relative increase in mean total enzyme content in each organ*

\begin{tabular}{|c|c|c|c|c|c|c|}
\hline & \multicolumn{2}{|c|}{ Lung } & \multicolumn{2}{|c|}{ Kidney } & \multicolumn{2}{|c|}{ Heart } \\
\hline & $20 \mathrm{~d} / 18 \mathrm{~d}$ & $22 \mathrm{~d} / 18 \mathrm{~d}$ & $20 \mathrm{~d} / 18 \mathrm{~d}$ & $22 \mathrm{~d} / 18 \mathrm{~d}$ & $20 \mathrm{~d} / 18 \mathrm{~d}$ & $22 \mathrm{~d} / 18 \mathrm{~d}$ \\
\hline Organ wt & 2.5 & 3.5 & 3.6 & 6.3 & 2.2 & 3.8 \\
\hline \multicolumn{7}{|l|}{ Relative enzyme content } \\
\hline CuZnSOD & 2.6 & 5.3 & 5.9 & 13.8 & 3.0 & 5.4 \\
\hline $\mathrm{MnSOD}$ & 2.1 & 6.9 & 9.3 & 19.8 & 2.6 & 4.3 \\
\hline GPX & 2.5 & 4.8 & 6.8 & 16.9 & 2.7 & 6.5 \\
\hline CAT & 2.4 & 8.3 & 9.2 & 27.1 & 2.5 & 4.3 \\
\hline
\end{tabular}

* Mean organ content for each enzyme is calculated as the product of concentration of enzyme (per mg wet tissue) $\times$ mean organ wt (mg). Data are expressed as the ratio to each respective mean content at $18 \mathrm{~d}$ of gestation. Thus, the figures in the table represent relative increase in mean organ contents.

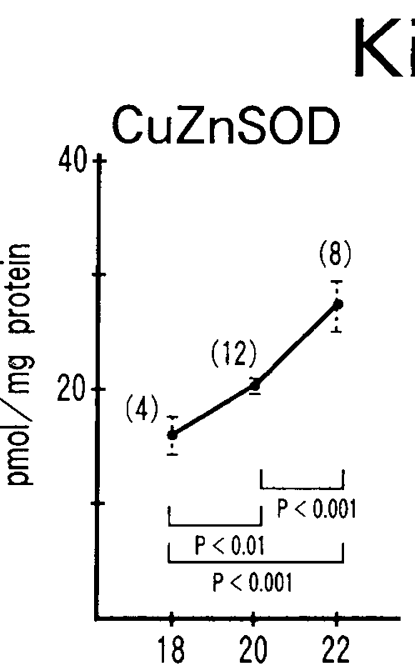

GESTATIONAL AGE (days)

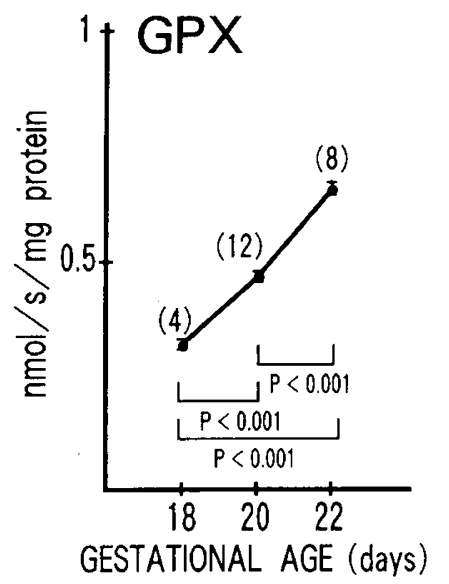

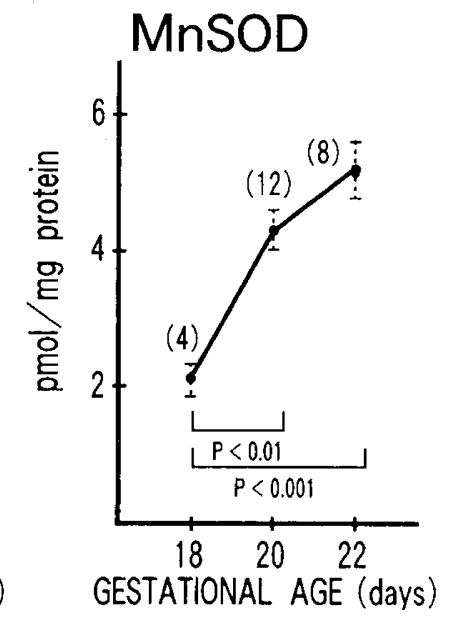

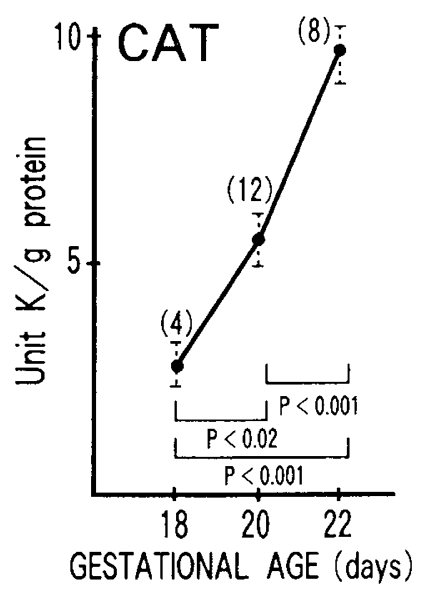

Fig. 2. Antioxidant enzymes in fetal rat kidney homogenates. The brackets indicate SEM. The abscissa represents gestational d. The figures in parentheses are the number of observations.

overall increase per kidney from d 18 to 22 was more than 10 fold for each enzyme.

Antixoidant enzymes in heart homogenate. In contrast to the stepwise increase observed in the lung and kidney, the concentrations of antioxidant enzymes in the heart were relatively stable during this period (Fig. 3). The only significant change observed was a mild increase in the GPX concentration from d 20 to 22 . The increase in the mean contents per organ was almost parallel to the organ growth rate.

\section{DISCUSSION}

Our study disclosed that the levels of antioxidant enzymes increased in a stepwise manner during late gestation not only in

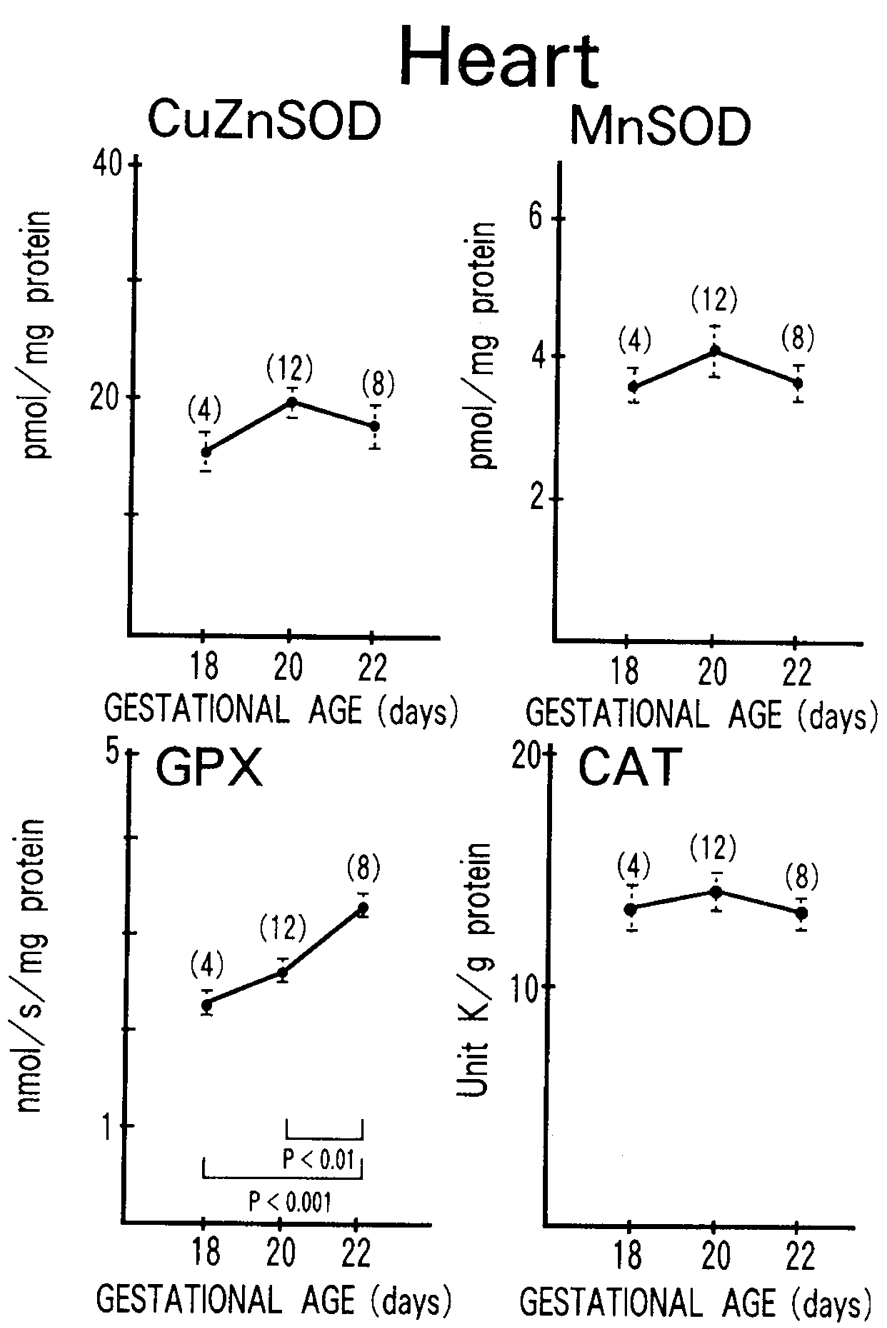

Fig. 3. Antioxidant enzymes in fetal rat heart homogenates. The brackets indicate SEM. The abscissa represents gestational d. The figures in parentheses are the number of observations.

the fetal rat lung, but also in the kidney. The magnitude of the change observed was different depending on the organ studied; the change was greater in the kidney than in the lung, and was much less remarkable in the heart. Several previous studies evaluated the prenatal development of antioxidant enzymes in rat lung (5-8), liver $(15,16)$, and brain (17). To our knowledge, there has been no previous report dealing with the prenatal development of antioxidant enzymes in fetal rat kidney or heart.

It is known that a rapid structural development takes place in fetal rat lung and kidney from d 18 to 22 . In the lung, peripheral branching and lengthening of terminal tubules and marked widening of the air spaces results in the formation of acini with airblood barriers (18). The alveolar epithelial cells begin to differ- 
entiate into several types. In the kidney, juxtamedullary nephrons are formed mainly during this period (19). In both organs, further structural development proceeds in the postnatal period. In contrast, both structural and functional development of the heart occurs mainly in the early gestational period, with minimal structural development thereafter (20). The heart exhibits the general external shape of the adult heart by the end of the embryonic stage (20). Our findings that the antioxidant enzymes increased rapidly in the kidney and lung but minimally in the heart during late gestation may be related to a different profile of tissue development in the heart from that in the kidney and lung. Tissue development is characterized by cellular differentiation. Studies on a wide variety of cell types indicate that total SOD increases during cellular differentiation (18). Both CAT and GPX have also been reported to increase in certain less generalized cell types during development (21). Thus, tissue development is postulated to be associated with an increase in antioxidant capacity. Whether this increase is a general phenomenon and occurs in all cell types or is confined to specific cell types needs to be determined in further studies.

Both GPX and CAT in fetal rat lung have been reported to increase almost 2 -fold in the last $2 \mathrm{~d}$ of gestation $(5,6)$. From $\mathrm{d}$ 18 to 22 , they were found to increase 5 -fold by Tanswell et al. (7), and approximately 2.5 -fold by Gerdin et al. (8), the magnitude of the changes in the latter study being similar to that observed here. On the other hand, the increase in SOD described in these studies appears to be less consistent than the increase in GPX and CAT. Total SOD activity increased approximately 1.5fold in the last $2 \mathrm{~d}$ of gestation in the two studies $(5,6)$. Only Tanswell et al. (7) and Gerdin et al. (8) attempted to measure the activities of CuZnSOD and MnSOD separately in the fetal rat lung. According to the former authors, the CuZnSOD increased 10-fold but MnSOD, the predominant SOD in fetal lung by their assay, decreased concurrently. As a whole, total SOD activity was increased only $20 \%$ in their series of experiments. Likewise, Gerdin et al. (8) observed that total SOD activity was increased only $30 \%$. However, they found that MnSOD represented about $30 \%$ of the total SOD activity, and speculated that the discrepancy between Tanswell et al.'s data and theirs was due to the different biologic activity assays used.

To resolve this contradiction, Gerdin et al. (8) noted the need for the use of specific immunoassays for CuZnSOD and MnSOD, as were used here. Our study revealed that immunoreactive MnSOD represented about $15 \%$ of the total SOD in the fetal lung, and that both CuZnSOD and MnSOD increased significantly from d 18 to 22 . Thus, the four antioxidant enzymes in the fetal lung studied here increased simultaneously during the late gestational period. We have observed in hyperthyroid rat muscles that a sole increase in MnSOD not accompanied by a concurrent increase in the other antioxidant enzymes did not protect the tissues against oxidant challenge (13). It is also hypothesized that the induction of antioxidant enzymes must be balanced to be effective (22). Thus, the balanced increase observed here would enhance the antioxidant capacity of the cells.

The relative increase in mean total enzyme content from d 18 to 22 was less than 10 -fold in the lung and greater than 10 -fold in the kidney for each antioxidant enzyme. The drastic increase in the kidney enzymes during the late gestational period suggests that prenatal maturation of antioxidant capacity occurs later in the kidney than in the lung and, accordingly, that the fetal rat kidney is very immature in terms of antioxidant capacity. As suggested in the fetal rat lung (5-8), the immaturity of antioxidant capacity revealed by our study could make the fetal rat kidney vulnerable to free radical-mediated injury. Accumulating experimental evidence suggests that ischemia-reperfusion injury mediated by active oxygen species can be a mechanism of renal tubular damage, leading to acute tubular necrosis $(3,23)$. Perinatal asphyxia and hypoxia is known to accompany ischemic renal dysfunction (24). We cannot extrapolate the development of antioxidant enzymes in human fetus from the results obtained in the rat. Although our results support the contention that free radical-mediated injury could be a mechanism for the perinatal ischemic renal damage, the pathophysiologic implications of the rapid increase in the kidney antioxidant enzymes observed here still need to be elucidated.

Acknowledgment. The authors gratefully acknowledge the technical assistance of Teiko Niitsu.

\section{REFERENCES}

1. Haatdavoudi G, O’Neill JJ, Barry BE, Freeman BA, Crapo JD 1981 Pulmonary injury in rats following continuous exposure to $60 \% \mathrm{O}_{2}$ for 7 days. J Appl Physiol 51:1220-1231

2. Simpson PT, Lucchesi BR 1987 Free radicals and myocardial ischemia and reperfusion injury. J Lab Clin Med 110:13-30

3. Paller MS, Hoidal JR, Ferris TF 1984 Oxygen free radicals in ischemic acute renal failure in the rat. J Clin Invest 74:1156-1164

4. Frank L, Sosenko IRS 1987 Development of lung antioxidant enzyme system in late gestation: possible implications for the prematurely born infant. $J$ Pediatr 110:9-14

5. Yam J, Frank L., Roberts RJ 1978 Age-related development of pulmonary antioxidant enzymes in the rat. Proc Soc Exp Biol Med 157:293-296

6. Yoshioka T, Shimada T, Sekiba K 1980 Lipid peroxidation and antioxidants in the rat lung during development. Biol Neonate 38:161-168

7. Tanswell AK, Freeman BA 1984 Pulmonary antioxidant enzyme maturation in the fetal rat. I. Developmental profiles. Pediatr Res 18:584-587

8. Gerdin E, Tyden O, Eriksson UJ 1985 The development of antioxidant enzymatic defense in the perinatal rat lung: activities of superoxide dismutase, glutathione peroxidase, and catalase. Pediatr Res 19:687-691

9. Asayama K, Sharp RA, Burr IM 1985 Purification and radioimmunoassays for superoxide dismutases in the mouse: tissue concentrations in different strains. Int J Biochem 17:1171-1178

10. Asayama K, Burr IM 1985 Rat superoxide dismutases: purification, labeling, immunoassay and tissue concentration. J Biol Chem 260:2212-2217

11. Asayama K, Dettbarn WD, Burr IM 1986 Differential effect of denervation on free-radical scavenging enzymes in slow and fast muscle of rat. J Neurochem 46:604-609

12. Thomson JF, Nance SL, Tollaksen SL 1978 Spectrophotometric assay of catalase with perborate as substrate. Proc Soc Exp Biol Med 157:33-35

13. Asayama K, Dobashi K, Hayashibe H, Megata Y, Kato K 1987 Lipid peroxidation and free radical scavengers in thyroid dysfunction in the rat: possible mechanism of injury to heart and skeletal muscle in hyperthryoidism. Endocrinology 121:2112-2118

14. Lowry OH, Rosebrough NJ, Farr AL, Randall AJ 1951 Protein measurement with the Folin phenol reagent. J Biol Chem 193:265-274

15. Yoshioka $\mathrm{T}$, Takehara $\mathrm{Y}$, Shimatani M, Abe K, Utsumi K 1982 Lipid peroxidation and antioxidants in rat liver during development. Tohoku J Exp Med 137:391-400

16. Mavelli I, Autuori F, Dini L, Spinedi A, Criolo MR, Rotilio G 1981 Correlation between superoxide dismutase, glutathione peroxidase and catalase in isolated rat hepatocytes during fetal development. Biochem Biophys Res Commun 102:911-916

17. Scarpa M, Rigo A, Viglino P. Stevanato R, Bracco F, Battistin L 1987 Age dependence of the level of the enzymes involved in the protection against active oxygen species in the rat brain. Proc Soc Exp Biol Med 185:129-133

18. Ballard PL 1986 Lung development. In: Ballard PL (ed) Hormones and Lung Maturation. Springer-Verlag, New York, pp 1-23

19. Speller AM, Moffat DB 1977 Tubulo-vascular relationships in the developing kidney. J Anat 123:487-500

20. Arey LB 1974 The heart and circulation changes. In: Arey LB (ed) Developmental Anatomy, 7 th ed. Saunders. Philadelphia, pp 375-395

21. Allen RG, Balin AK 1989 Oxidative influence on development and differentiation: an overview of a free radical theory of development. Free Radical Biol Med 6:631-661

22. Scott MD, Meshnick SR, Eaton JW 1987 Superoxide dismutase-rich bacteria Paradoxical increase in oxidant toxicity. J Biol Chem 262:3640-3645

23. Canavese C, Stratta P, Vercellone A 1988 The case for oxygen free radicals in the pathogenesis of ischemic acute renal failure. Nephron 49:9-15

24. Dauber IM, Krauss AN, Symchych PS, Auld PAM 1976 Renal failure following perinatal anoxia. J Pediatr 83:933-940 